\title{
PERBANDINGAN KEMAMPUAN PENALARAN MATEMATIS ANTARA SISWA YANG BELAJARNYA MENGGUNAKAN PENDEKATAN INKUIRI DENGAN SETING KOOPERATIF TIPE JIGSAW DENGAN MODEL PEMBELAJARAN BIASA
}

\author{
Lessa Roesdiana \\ Program Studi Pendidikan Matematika, FKIP, Universitas Singaperbangsa Karawang \\ Email: Lessa.Roesdiana@yahoo.com, lessa.roesdiana@fkip.unsika.ac.id
}

\begin{abstract}
ABSTRAK
Kemampuan siswa dalam memecahkan masalah matematika merupakan aspek yang sangat penting dalam belajar matematika. Oleh karena itu, untuk meningkatkan kemampuan penalaran matematis siswa diperlukan suatu strategi yang tepat dalam kegiatan pembelajaran agar hasil belajar siswa lebih optimal. Salah satu model pembelajaran yang dapat digunakan menggunakan pendekatan inkuiri dengan tipe jigsaw.

Penelitian ini merupakan penelitian kuasi eksperimen dengan desain kelompok kontrol pretest-postest. Populasi penelitian ini adalah siswa kelas X SMA Negeri 3 Karawang . Dimana instrumen pengujiannya berupa soal uraian yang memenuhi uji validitas dan reliabilitas yang baik dengan taraf signifikan $\alpha=0,05$. Dari keseluruhan proses dapat disimpulkan bahwa menggunaan tipe jigsaw dapat meningkatkan kemampuan penalaran matematis siswa dibandingkan dengan pembelajaran biasa.
\end{abstract}

Kata kunci : Penalaran Matematis, Tipe Jigsaw, Pembelajaran Biasa

\begin{abstract}
The Ability of students in solving mathematical problems was a very important aspect in learning mathematics. Therefore, to improve students'mathematical reasoning ability, it was need an appropriate strategy in learning activities to make an optimality in the result of students'learning. One of the learning model that can be used was inquiry approach of jigsaw type.

The study was a quasi-experimental study with pretes-posttest control group design. The population of this study was the students of class X in SMA Negeri 3 Karawang. The instrument that was used in this study was an essay test that appropriate with a good validity and reliability with a significant level $\alpha=0,05$. From the whole process, it could be concluded that using jigsaw type can improve students'mathematical reasoning ability compared with ordinary learning.
\end{abstract}

Keyword : Mathematical Reasoning, Jigsaw Type, Learning Model 


\section{Pendahuluan}

Pembelajaran yang didapat oleh siswa selama sekolah seharusnya berupa pengalaman yang dapat digunakan untuk bekal hidup dan untuk bertahan hidup. Tugas seorang guru disini bukan hanya sekedar mengajar tetapi lebih ditekankan pada membelajarkan dan mendidik. Pembelajaran tidak hanya ditekankan pada keilmuannya semata. Arah pembelajaran seharusnya berfokus pada belajar, seperti: siswa tidak hanya untuk mengetahui

sesuatu

(learning to know about) tetapi juga belajar melakukan (learning to do), belajar menjiwai (learning to be), dan bagaimana seharusnya belajar (learning to learn), serta belajar bersosialisasi dengan sesama teman (how to live together).

Matematika merupakan suatu ilmu yang terintegrasi baik antar konsepnya dengan disiplin ilmu lain maupun dalam kehidupan sehari-hari. Maka guru harus berperan dalam upaya meningkatkan kemampuan siswa dalam menerapkan konsep-konsep matematika serta kemampuan berpikir matematika yang telah ia pelajari ke dalam masalahmasalah yang berkaitan dengannya (dikenal dengan istilah koneksi matematika).

Perbandingan ... (Lessa Roesdiana)
Salah satu caranya yaitu dengan memberikan bekal dasar-dasar kecakapan hidup (life skill)/ kompetensi dasar, yaitu kemampuan pemecahan masalah, komunikasi serta penalaran sebagaimana tercakup dalam tujuan pembelajaran pada kurikulum berbasis kompetensi. Dengan bekal tersebut siswa diharapkan dapat mengetahui dari mana harus memulai dan apa yang harus dilakukan agar dapat mengatasi permasalahannya. Kemampuankemampuan tersebut dapat dikembangkan oleh guru dengan cara mengembangkan suatu model pembelajaran yang memuat dasar-dasar life skill. Dan didalam pembelajaran matematika, model pembelajaran tersebut juga harus dapat memfasilitasi minat serta motivasi siswa terhadap matematika. Sehingga pada saatnya nanti siswa dapat mengaplikasikan konsep matematika yang telah ia pelajari dalam kehidupan sehari-hari.

$$
\text { Ruseffendi (1982: }
$$
menyatakan bahwa "Matematika bagi anak-anak pada umumnya merupakan mata pelajaran yang tidak disenangi kalau bukan mata pelajaran yang dibenci." Anggapan tersebut sudah melekat pada anak-anak, sehingga berdampak buruk terhadap proses AdMathEdu | Vol.7 No.2 | Desember 2017 
pembelajaran siswa dalam matematika. Pada akhirnya mengakibatkan prestasi dalam pembelajaran matematika menjadi kurang memuaskan. Karena matematika merupakan salah satu ilmu yang berguna dan menjadi salah satu bidang studi yang wajib disetiap tingkat sekolah, maka anggapan tersebut harus dihilangkan. Menurut Dimyati dan Mudjono (2002: 43) bahwa: "Guru mempunyai kewajiban untuk bisa menanamkan sikap positif pada siswa terhadap mata pelajaran yang menjadi tanggung jawabnya". Namun tidaklah mudah untuk menumbuhkan sikap positif terhadap matematika tanpa ada minat dalam diri seseorang, karena sikap yang tumbuh merupakan akibat dari minat. Untuk itu dalam proses belajar matematika di kelas, guru harus mampu mendesain perangkat pembelajaran, cara penyajian atau cara penyampaian, cara bertanya, bahkan cara memberi bimbingan harus menarik bagi siswa. Sehingga muncul ketertarikan dan minat yang pada akhirnya dapat menumbuhkan sikap positif dalam diri siswa terhadap matematika.

Wahyudin (Hendriana, 2002) pula mengungkapkan bahwa: "Matematika merupakan mata pelajaran yang sukar dipahami, sehingga ketidaksenangan terhadap pelajaran matematika kemungkinan disebabkan oleh sukarnya memahami mata pelajaran matematika". Padahal banyak ilmu yang pengembangannya bergantung pada matematika. Orang yang berkepentingan dengan matematika, walaupun matematika dikenal sebagai ilmu yang sukar dipahami, akan mencari cara terbaik bagaimana mempelajarinya.

Salah satu upaya guru untuk meningkatkan aktivitas dan prestasi belajar siswa adalah memilih suatu strategi pembelajaran yang lebih efektif. Untuk mencapai tujuan tersebut, peneliti ingin mencoba menerapkan suatu strategi pembelajaran, yaitu model pembelajaran kooperatif. Dari tujuh tipe pembelajaran kooperatif, peneliti memilih tipe pembelajaran model Jigsaw-II dengan pertimbangan bahwa menurut Slavin tipe Jigsaw-II digunakan terutama pada ilmu-ilmu sosial. Atas dasar itu, peneliti ingin mengetahui pengaruh tipe pembelajaran Jigsaw-II terhadap hasil belajar siswa pada ilmu-ilmu eksakta yang dalam hal ini adalah matematika. 


\section{Metode Penelitian}

Metode yang digunakan dalam penelitian ini adalah metode eksperimen (eksperimental method). Penggunaan metode ini bertujuan untuk mengetahui sejauh mana pengaruh variabel bebas terhadap variabel terikat. Dalam penelitian ini yang menjadi variabel bebas adalah model pembelajaran kooperatif tipe jigsaw, sedangkan variabel terikatnya adalah kemampuan

\section{Hasil dan Pembahasan}

\section{Hasil Penelitian}

Data yang diperoleh dalam penelitian ini adalah data nilai tes hasil belajar matematika siswa. Selanjutnya peneliti mengolah data tersebut sesuai dengan langkah-langkah yang sudah ditentukan. Data yang diperoleh berasal dari data kuantitatif, pengolahan data penalaran matematis siswa. Sehingga disain penelitiannya adalah sebagai berikut :
A
$\mathrm{O} \quad \mathrm{X}$
$\mathrm{O}$
A $\mathrm{O}$
$\mathrm{O}$

Keterangan:

$\mathrm{A}=$ Pengambilan sampel secara acak menurut kelas

$\mathrm{O}=$ pretes - postes

$\mathrm{X}=$ perlakuan

Tabel 1. Deskripsi Hasil Penelitian

\begin{tabular}{lllllll}
\hline Metode & \multicolumn{7}{l}{ Pretes } & \multicolumn{5}{c}{ Postes } \\
\cline { 2 - 7 } & $\mathrm{X}$ & SD & $\begin{array}{l}\text { SMI } \\
(\%)\end{array}$ & X & SD & $\begin{array}{l}\text { SMI } \\
(\%)\end{array}$ \\
$\begin{array}{l}\text { Kelas } \\
\text { Eksperimen }\end{array}$ & 18,80 & 6,82 & 8,80 & 25,47 & 3,00 & 25,47 \\
Kelas Kontrol & 19,07 & 6,41 & 9,07 & 21,17 & 4,56 & 21,17 \\
\hline
\end{tabular}

Berdasarkan tabel 1 maka dapat diasumsikan bahwa kemampuan yang pembelajarannya menggunakan Metode Jigsaw lebih baik daripada kuantitatif dilakukan dengan menggunakan sofware Minitab 16.

Dari hasil pengolahan data untuk masing-masing kelompok diperoleh data seperti pada Tabel 1 . terlihat dari rata-rata postes eksperimen lebih besar dari postes kontrol. 


\section{Analisis Data Tes Awal}

1. Uji Normalitas

Kriteria pengujian : Jika $\mathrm{P} \geq 0.05 \quad$ Dengan menggunakan uji kolmogorov maka sampel berdistribusi normal. smirnov dapat dilihat seperti pada Tabel 2.

Tabel 2. Hasil Uji Normalitas Skor Pretes

\begin{tabular}{lcccccc}
\hline $\begin{array}{l}\text { Kelompok siswa } \\
\text { yang } \\
\text { memperoleh } \\
\text { pendekatan }\end{array}$ & $\bar{x}$ & $\mathbf{S}$ & $\mathbf{N}$ & $\mathbf{K S}$ & $\begin{array}{l}\mathbf{P}- \\
\text { Value }\end{array}$ & Interpretasi \\
\hline Kelas Kontrol & 19,07 & 6,40 & 40 & 0,095 & 0,150 & Ho diterima \\
& & 7 & & & & Ho diterima \\
$\begin{array}{l}\text { Kelas } \\
\text { Ekperimen }\end{array}$ & 18,80 & 6,82 & 40 & 0,099 & 0,150 & \\
\hline
\end{tabular}

Berdasarkan tabel 2 terlihat nilai kedua kelompok lebih dari 0,05 maka probabilitas pada kolom signifikansi dapat dikatakan bahwa kelompok untuk kelompok eksperimen (Jigsaw) peksperimen dan kelompok kontrol value $=0,150 \geq 0.05$ dan kelas kontrol berarti sampel berasal dari populasi (pembelajaran biasa) $\mathrm{p}$-value $=0,150 \geq \quad$ yang berdistribusi normal.

0.05. Oleh karena niilai probabilitas

2. Uji Homogenitas

Kriteria pengujian : Jika $\mathrm{P}>0.05$

Uji Homogenitas Dua Varians dapat maka sampel berdistribusi normal. Nilai dilihat seperti pada Tabel 3.

Tabel 3. Hasil Uji Normalitas Skor Pretes Kelompok Eksperimen dan Kelompok Kontrol

\begin{tabular}{lrrrr}
\hline & $\begin{array}{l}\text { Statist } \\
\text { ic }\end{array}$ & df1 & df2 & P-Value \\
& 0,29 & 1 & 78 & 0,589 \\
$\begin{array}{l}\text { Levene's } \\
\text { Test }\end{array}$ & & & & \\
\hline
\end{tabular}

Berdasarkan uji homogenitas varians dengan menggunakan uji Levene pada Tabel 3 di atas, terlihat bahwa nilai probabilitas pada kolom signifikansi sebesar $p$-value $=0,589 \geq 0.05$. Maka dapat diambil kesimpulan bahwa siswa 
kelas eksperimen dan kelas kontrol berasal dari populasi-populasi yang

3. Uji-t

Karena sampel berasal dari populasi berdistribusi normal dan memiliki varians yang homogen maka

$$
\begin{array}{ll}
\mathrm{H}_{0} & : \mu_{1}=\mu_{2} \\
\mathrm{H}_{1} & : \mu_{1} \neq \mu_{2}
\end{array}
$$

Setelah dilakukan pengolahan data, dapat dilihat seperti pada Tabel 4.

\begin{tabular}{|c|c|c|c|c|c|c|}
\hline \multirow{2}{*}{$\begin{array}{l}\text { Kelompok siswa } \\
\text { yang memperoleh } \\
\text { pendekatan }\end{array}$} & \multirow[b]{2}{*}{$\bar{x}$} & \multirow[t]{2}{*}{$\mathbf{S}$} & \multirow[t]{2}{*}{$\mathbf{N}$} & \multicolumn{2}{|l|}{ Uji-T } & \multirow[t]{2}{*}{ Interpretasi } \\
\hline & & & & $\mathrm{t}$ hit & $\begin{array}{l}\text { P- } \\
\text { Value }\end{array}$ & \\
\hline Kelas Kontrol & 19,07 & 6,41 & 40 & -0.19 & 0.853 & Ho diterima \\
\hline Kelas Ekperimen & 18,80 & 6,82 & 40 & -0.19 & 0.853 & Ho diterima \\
\hline
\end{tabular}

Tabel 4. Hasil Uji-t Skor Pretes

Jika probabilitas > 0,05 maka $\mathrm{H}_{0}$ diterima, sebaliknya jika probabilitas < 0,05 maka $\mathrm{H}_{0}$ ditolak. Berdasarka $\mathrm{n}$ hasil perhitungan diatas pada tabel 4 terlihat bahwa $\mathrm{p}$-value $\geq 0.05$ maka Ho diterima ( $p$-value $=0,853 \geq 0.05)$. mempunyai varians sama, atau kedua kelompok tersebut homogen.

dilakukan uji signifikansi perbedaan dua rata-rata dengan menggunakan uji-t, hipotesisnya sebagai berikut : 
Berdasarkan tabel 5 terlihat nilai probabilitas pada kolom signifikansi untuk kelompok eksperimen (Jigsaw II) p-value $=0,052 \geq 0.05$ dan kelas kontrol (pembelajaran biasa) $\mathrm{p}$-value $=$ $0,150 \geq 0.05$. Oleh karena nilai probabilitas kedua kelompok lebih dari 0,05 maka dapat dikatakan bahwa kelompok eksperimen dan kelompok kontrol berarti sampel berasal dari populasi yang berdistribusi normal.

Uji Homogenitas

Kriteria pengujian : Jika $\mathrm{P} \geq 0.05$ maka sampel berdistribusi normal. Nilai Uji Homogenitas Dua Varians dapat dilihat seperti pada Tabel 6 .

Tabel 6. Output Uji Homogenitas Dua Varians Tes Akhir (Postes) Kelompok Eksperimen dan Kelompok Kontrol

\begin{tabular}{lllll}
\hline & Statisti & df1 & df2 & P-Value \\
& & & & \\
\hline $\begin{array}{l}\text { Levene's } \\
\text { Test }\end{array}$ & 4,00 & 1 & 78 & 0,050 \\
\hline
\end{tabular}

Berdasarkan uji homogenitas varians dengan menggunakan uji Levene pada Tabel 6 di atas, jika nilai signifikansi atau nilai probabilitas > 0,05 , data berasal dari populasi-populasi yang mempunyai varians sama. Terlihat bahwa nilai probabilitas pada kolom signifikansi sebesar $\mathrm{p}$-value $=0,050 \geq$ 0.05. Maka dapat diambil kesimpulan bahwa siswa kelas eksperimen dan kelas kontrol berasal dari populasi-populasi yang mempunyai varians sama, atau kedua kelompok tersebut homogen.
Uji-t

Karena sampel berasal dari populasi berdistribusi normal dan memiliki varians yang homogen maka dilakukan uji signifikansi perbedaan dua rata-rata dengan menggunakan uji-t, hipotesisnya sebagai berikut:

$$
\begin{array}{ll}
\mathrm{H}_{0} & : \mu_{1}=\mu_{2} \\
\mathrm{H}_{1} & : \mu_{1} \neq \mu_{2}
\end{array}
$$

Setelah dilakukan pengolahan data, dapat dilihat seperti pada Tabel 
Tabel 7. Output Uji -t Tes Akhir (Postes)

Kelompok Eksperimen dan Kelompok Kontrol

\begin{tabular}{|c|c|c|c|c|c|c|}
\hline \multirow{2}{*}{$\begin{array}{l}\text { Kelompok } \\
\text { siswa yang } \\
\text { memperoleh } \\
\text { pendekatan }\end{array}$} & \multirow{2}{*}{$\bar{x}$} & \multirow[t]{2}{*}{$\mathbf{S}$} & \multirow[t]{2}{*}{$\mathbf{N}$} & \multicolumn{2}{|l|}{ Uji-T } & \multirow{2}{*}{$\begin{array}{l}\text { Interpret } \\
\text { asi }\end{array}$} \\
\hline & & & & hitung & $\begin{array}{l}\text { P- } \\
\text { Valu } \\
\text { e }\end{array}$ & \\
\hline Kelas Kontrol & 21,17 & 4,562 & 40 & 4,72 & $\begin{array}{l}0,00 \\
0\end{array}$ & Ho ditolak \\
\hline $\begin{array}{l}\text { Kelas } \\
\text { Ekperimen }\end{array}$ & 25,47 & 3,000 & 40 & 4,72 & $\begin{array}{l}0,00 \\
0\end{array}$ & Ho ditolak \\
\hline
\end{tabular}

Jika probabilitas > 0,05 maka $\mathrm{H}_{0}$ diterima, sebaliknya jika probabilitas < 0,05 maka $\mathrm{H}_{0}$ ditolak. Berdasarkan hasil perhitungan diatas pada tabel 7 terlihat bahwa $\mathrm{p}$-value $\leqq 0.05$ maka Ho ditolak (p-value $=0,000 \leqq 0.05)$.

Penelitian ini menggunakan perbedaan perlakuan antara kelas kontrol dengan kelas eksperimen. Kelas kontrol menggunakan model pembelajaran biasa, sedangkan kelas eksperimen menggunakan pendekatan pembelajaran tipe jigsaw. Berdasarkan hasil analisis data diperoleh bahwa kelas eksperimen mempunyai nilai rata-rata yang lebih baik daripada kelas kontrol. Berdasarkan pengujian diperoleh kesimpulan bahwa kemampuan penalaran matematis siswa SMA yang menggunakan pendekatan Pembelajaran tipe jigsaw lebih baik daripada yang menggunakan pembelajaran biasa.

Perbandingan ... (Lessa Roesdiana)

\section{Kesimpulan}

Berdasarkan hasil analisis data dan pengujian hipotesis, bahwa kemampuan penalaran matematis siswa dilihat dari nilai postes sangat berbeda antara kelas eksperimen dan kelas kontrol. Maka dapat disimpulkan bahwa peningkatan kemampuan penalaran matematis siswa yang belajarnya menggunakan model pembelajaran kooperatif tipe jigsaw lebih baik daripada siswa yang belajarnya menggunakan model pembelajaran biasa.

\section{Pustaka}

Arends, R. (1997). Classroom Intructional Management. The Mc Graw Hill Company. New York.

Arikunto, S. (1998). Prosedur Penelitian Suatu Pendekatan dan Praktek. Jakarta: Rineka Cipta.

Dimyati dan Mudjiono. (2002). Belajar dan Pembelajaran. Jakarta: Rineka Cipta. 
Rahmawati, A. (2010). Meningkatkan Kemampuan Penalaran Adaptif Siswa Sekolah Menengah Atas Melalui Pemodelan Berbasis Realistic Mathematics Education. Skripsi FPMIPA UPI. Bandung: Tidak diterbitkan

Ruseffendi, ET. (1982). Dasar-Dasar Matematika Modern untuk Guru. Bandung: Tarsito.

Ruseffendi, E. T. (2001). Dasar-dasar Penelitian Pendidikan dan Bidang Non-Eksakta lainnya. Semarang: IKIP Semarang Press. 
